\title{
Nanoporous Calcium Silicate and PLGA Biocomposite for Bone Repair
}

\author{
Jiacan Su, ${ }^{1}$ Zhiwei Wang, ${ }^{1}$ Yonggang Yan, ${ }^{2}$ Yongfa Wu, ${ }^{1}$ Liehu Cao, ${ }^{1}$ Yuhai Ma, ${ }^{1}$ \\ Baoqing Yu, ${ }^{1}$ and Ming $\mathrm{Li}^{1}$ \\ ${ }^{1}$ Department of Orthopaedics, Changhai Hospital, Second Military Medical University, Shanghai 200433, China \\ ${ }^{2}$ School of Physical Science and Technology, Sichuan University, Chengdu 610064, China
}

Correspondence should be addressed to Jiacan Su, jiacansu@yahoo.cn

Received 28 April 2010; Revised 1 September 2010; Accepted 3 September 2010

Academic Editor: Hongchen Chen Gu

Copyright (C) 2010 Jiacan Su et al. This is an open access article distributed under the Creative Commons Attribution License, which permits unrestricted use, distribution, and reproduction in any medium, provided the original work is properly cited.

\begin{abstract}
Nanoporous calcium silicate (n-CS) with high surface area was synthesized using the mixed surfactants of $\mathrm{EO}_{20} \mathrm{PO}_{70} \mathrm{EO}_{20}$ (polyethylene oxide $)_{20}$ (polypropylene oxide $)_{70}$ (polyethylene oxide $)_{20}, \mathrm{P} 123$ ) and hexadecyltrimethyl ammonium bromide (CTAB) as templates, and its composite with poly(lactic acid-co-glycolic acid) (PLGA) were fabricated. The results showed that the $\mathrm{n}$ CS/PLGA composite ( $n$-CPC) with $20 \mathrm{wt} \% \mathrm{n}$-CS could induce a dense and continuous layer of apatite on its surface after soaking in simulated body fluid (SBF) for 1 week, suggesting the excellent in vitro bioactivity. The n-CPC could promote cell attachment on its surfaces. In addition, the proliferation ratio of $\mathrm{MG}_{63}$ cells on $\mathrm{n}-\mathrm{CPC}$ was significantly higher than PLGA; the results demonstrated that $\mathrm{n}$-CPC had excellent cytocompatibility. We prepared n-CPC scaffolds that contained open and interconnected macropores ranging in size from 200 to $500 \mu \mathrm{m}$. The n-CPC scaffolds were implanted in femur bone defect of rabbits, and the in vivo biocompatibility and osteogenicity of the scaffolds were investigated. The results indicated that $\mathrm{n}$-CPC scaffolds exhibited good biocompatibility, degradability, and osteogenesis in vivo. Collectively, these results suggested that the incorporation of n-CS in PLGA produced biocomposites with improved bioactivity and biocompatibility.
\end{abstract}

\section{Introduction}

Calcium silicate (CS) biomaterials exhibit excellent in vitro bioactivity, and the apatite formation rate on its surface is faster than those of other biocompatible glasses and glass ceramics in simulated body fluid (SBF) [1-3]. In addition, CS bioceramics, CS composites plasma sprayed on titanium alloy, and CS/polymer composites showed good bioactivity, providing favorable implants for bone tissue regeneration [4-6]. Although the existing bioactive CS biomaterials possess high bioactivity, they are unfortunately very brittle and difficult for processing.

PLGA, one of the most commercially available polymers, is widely used in biomedical fields for its degradability, biocompatibility, and formability [7]. However, some problems have been encountered regarding the use of the polymer for bone regeneration. The primary limiting factor is the lack of bioactivity, which prevents new tissue from attaching to the polymer surface [8]. To date, a variety of bioactive composites of degradable polymers, bioceramics, and bioactive glasses have shown varying degrees of success as implants for bone tissue repair $[9,10]$.

In the recent years, the nanoporous materials with high specific surface area have received much interest because of their potential applications in catalysts, optical devices, and so forth [11]. In biomedical researches, nanoporous materials have been mainly investigated for use in drug delivery [12]. Previous study showed that increasing the specific surface area and pore volume of biomaterials might greatly accelerate the kinetic process of apatite deposition and therefore, improve the bone-forming bioactivity [13]. Recently, there have been some studies in the literature focusing on the composites created by combining polymers and calcium silicate [14-16].

To our knowledge, there were no previous reports about the preparation of nanoporous CS/PLGA composite ( $\mathrm{n}$ CPC) as bone repair materials. It is expected that the biological performances of polymer-based composite should 
be improved if n-CS with high specific surface area and pore volume was incorporated into PLGA. Therefore, $\mathrm{n}-\mathrm{CPC}$ was prepared and its bioactivity and biocompatibility both in vitro and vivo were investigated in this study.

\section{Materials and Methods}

2.1. Preparation and Characterization of $n$-CS. The nanoporous calcium silicate ( $\mathrm{n}-\mathrm{CS}$ ) was prepared by sol-gel method. The mixed surfactants of $8 \mathrm{~g} \mathrm{EO}{ }_{20} \mathrm{PO}_{70} \mathrm{EO}_{20}$ (polyethylene oxide) ${ }_{20}$ (polypropylene oxide) ${ }_{70}$ (polyethylene oxide) $)_{20}, \mathrm{P} 123$ ) and $10 \mathrm{~g}$ hexadecyltrimethyl ammonium bromide (CTAB) were dissolved in $480 \mathrm{~mL}$ of $2 \mathrm{M} \mathrm{HCl}$ and $120 \mathrm{~mL}$ of distilled water solution while stirring at $37^{\circ} \mathrm{C}$ in water bath until the solution became clear. $36.8 \mathrm{~mL}$ of tetraethyl orthosilicate (TEOS) and $38.6 \mathrm{~g}$ of $\mathrm{Ca}\left(\mathrm{NO}_{3}\right)_{2} \cdot 4 \mathrm{H}_{2} \mathrm{O}$ were then added into the solution. The mixture was stirred at room temperature for $24 \mathrm{~h}$, and the resulting product was dried at $50^{\circ} \mathrm{C}$ for $48 \mathrm{~h}$ in air without any filtering or washing. After that, the n-CS was calcined at $600^{\circ} \mathrm{C}$ for $2 \mathrm{~h}$ to remove the mixed surfactants (templates), and the final n-CS products were obtained, then the n-CS were ground into powders for further use. The morphology of n-CS was analyzed using TEM (JEM2010, Japan). $\mathrm{N}_{2}$ adsorption-desorption isotherms of n-CS powders were obtained using a Micromeritics porosimeter (Tristar 3000, USA). The surface area, pore size, and pore volume of n-CS were determined using Brunauer-Emmet-Teller (BET) and Barrett-Joyner-Halenda (BJH) analyses.

2.2. Preparation of $n-C P C$ and Its Scaffolds. The n-CPC with 20 wt $\%$ n-CS was fabricated by solvent-casting method. PLGA pellets (Sigma-Aldrich Corporation, St. Louis, USA) were dissolved in DMF at 20\% (w/v), a prescribed amount of $\mathrm{n}$-CS, according to the desired n-CS content, was then added to the PLGA/DMF solution under continuous stirring for $4 \mathrm{~h}$ to obtain uniform dispersion, resulting in n-CS/PLGA/DMF mixture. Subsequently, the mixture temperature was gradually increased to $120^{\circ} \mathrm{C}$ under constant stirring and held for $4 \mathrm{~h}$. The obtained mixture was cast in a $100 \times 100 \times 2 \mathrm{~mm}$ Teflon mold and air-dried under the fume hood for $48 \mathrm{~h}$ to evaporate the DMF. After washing with deionized water, the samples were dried at room temperature in a fume hood for $48 \mathrm{~h}$. The samples were cut to $\Phi 10 \times 2 \mathrm{~mm}$ for future use.

The n-CPC scaffolds with $20 \mathrm{wt} \% \mathrm{n}$-CS were prepared by solvent-casting and particulate-leaching methods. $10 \mathrm{~g} \mathrm{n}$ CPC (before preparation) was dissolved in $100 \mathrm{~mL}$ chloroform to form a mixture (suspension), and sodium chloride $(\mathrm{NaCl})$ was added as porogens (size: $200-500 \mu \mathrm{m}$; $\mathrm{NaCl} / \mathrm{n}$ $\mathrm{CPC}=8 / 1, \mathrm{w} / \mathrm{w}$ ) into the mixture (suspension), which was stirred continuously for $0.5 \mathrm{~h}$ and then cast into Teflon molds containing 60 wells $(\Phi 10 \times 5 \mathrm{~mm})$. The samples were dried at $37^{\circ} \mathrm{C}$ for $24 \mathrm{~h}$ to evaporate the chloroform. To leach out the salt, the dry samples were immersed in deionized water for $48 \mathrm{~h}$ at room temperature, with water changes approximately every $6 \mathrm{~h}$ for $4 \sim 5$ times. After washing with ethanol, the $\mathrm{n}$-CPC scaffolds were dried at room temperature in a fume hood for $48 \mathrm{~h}$ and stored in a desiccator until use.
2.3. Bioactivity in SBF. The bioactivity of n-CPC was evaluated by examining the apatite formation on its surface in SBF. SBF was prepared by dissolving reagent grade $\mathrm{NaCl}, \mathrm{NaHCO}_{3}, \mathrm{KCl}, \mathrm{K}_{2} \mathrm{HPO}_{4} \cdot 3 \mathrm{H}_{2} \mathrm{O}, \mathrm{MgCl}_{2} \cdot 6 \mathrm{H}_{2} \mathrm{O}$, $\mathrm{CaCl}_{2}$, and $\mathrm{Na}_{2} \mathrm{SO}_{4}$ in deionized water. The solution was buffered at $\mathrm{pH} 7.4$ with tris(hydroxymethyl) aminomethane $\left(\left(\mathrm{CH}_{2} \mathrm{OH}\right)_{3} \mathrm{CNH}_{2}\right)$ and $1 \mathrm{M}$ hydrochloric acid $(\mathrm{HCl})$ at $37^{\circ} \mathrm{C}$ [17]. $\mathrm{n}$-CPC dense samples $(\Phi 10 \times 2 \mathrm{~mm})$ were polished with diamond paste, then soaked in $30 \mathrm{~mL} \mathrm{SBF}$ at $37^{\circ} \mathrm{C}$ for 1 , $2,3,5$, and 7 days without shaking. After soaking, specimens were removed from the SBF solution, gently rinsed with deionized water, and dried at room temperature. X-ray diffraction (XRD, Geigerflex, Rigaku Co., Japan), scanning electron microscopy (FE-SEM, Hitachi Ltd, S-4300SE, JPN), and energy dispersive X-ray spectrometer (EDX) were used to monitor the surface morphology and phase composition of the n-CPC.

At each time point $(1,2,3,5$, and 7 days), the samples were taken out and the ion concentrations of calcium (Ca), phosphorus $(\mathrm{P})$, and silicon $(\mathrm{Si})$ in the SBF solution were tested using inductively coupled plasma-atomic emission spectroscopy (ICP-AES). In addition, the $\mathrm{pH}$ of the SBF solution was determined using an electrolyte-type $\mathrm{pH}$ meter at each time point. All the values obtained for three samples were averaged (mean $\pm \mathrm{SD})$.

2.4. Cell Attachment. The n-CPC and PLGA dense samples $(\Phi 10 \times 2 \mathrm{~mm})$ were used to determine the cell attachment on their surfaces, respectively, and tissue culture plate (TCP) as a control. The $\mathrm{MG}_{63}$ cells with a density of $2 \times 10^{3}$ were seeded on the samples located into 96well plate. The cell-seed samples were maintained at $37^{\circ} \mathrm{C}$ under $5 \% \mathrm{CO}_{2}$ condition for $4 \mathrm{~h}$, and then the culture medium was removed. Thereafter, the residual cultured medium and unattached cells were removed by washing with PBS three times. After the attached cells on the samples were digested by trypsin, the adherent cells were counted with a hemacytometer, and the cell attachment efficiency was determined by counting the number of cells remaining in the wells. Three replicates were carried out for each kind of sample, and the results were expressed as mean $\pm \mathrm{SD}$.

2.5. Cell Proliferation. The $\mathrm{MG}_{63}$ cells with a density of $2 \times 10^{3}$ were seeded on the n-CPC and PLGA samples $(\Phi 10 \times 3 \mathrm{~mm})$, respectively, which were located into 96well plate, followed by incubation for 1,3 , and 5 days. Viable cells on the samples were assessed quantitatively using the MTT assay. The sample-cell constructs were placed in culture medium containing MTT and incubated in a humidified atmosphere at $37^{\circ} \mathrm{C}$ for $4 \mathrm{~h}$. After the supernatants were removed, dimethyl sulfoxide (Sinopharm, Shanghai, China) was added to each well to completely dissolve the MTT reagent. The optical density (OD) of each well was measured at $590 \mathrm{~nm}$ in a microplate reader (ELX 800, Bio-Tek, USA) using a reference wavelength of $620 \mathrm{~nm}$. Six specimens of each kind of the samples were tested for each incubation period and expressed as mean $\pm \mathrm{SD}$. 
2.6. Histological Evaluation. sixteen healthy New Zealand white rabbits with an average weight of $2.8 \mathrm{~kg}$ were divided into 2 groups consisting of 8 animals. Under general anesthesia and sterile conditions, the left femur of each rabbit was exposed and one defect $(\Phi 6 \mathrm{~mm})$ was drilled in the distal part of the femur. The bone cavities were washed to eliminate bone debris and dried with gauze. Cylindrical n-CPC porous scaffolds with the size of $\Phi 6 \times$ $8 \mathrm{~mm}$ were implanted into the defects in the rabbit femora. Two animals of each group were sacrificed by an overdose abdominal injection of pentobarbital sodium 2, 4, 8, and 12 weeks after implantation. The bone specimens were harvested immediately after sacrifice. The samples together with surrounding tissues were excised, fixed in 10\% neutral buffered formalin, decalcified, and embedded in paraffin. Tissue blocks were sectioned at $5 \mu \mathrm{m}$ in thickness, stained with hematoxylin and eosine (H\&E) and then observed by light microscope (Olympus, Japan).

\section{Results}

3.1. Characterization of the $n$-CS. Figure 1 illustrates the transmission electron micrographs of the calcined n-CS. The TEM images show that the $\mathrm{n}$-CS with the pore size of around $4 \mathrm{~nm}$ had the ordered porous channels. It can be obtained that the prepared n-CS had a uniform nanoporous structure. $\mathrm{N}_{2}$ sorption isotherm of $\mathrm{n}-\mathrm{CS}$ is shown in Figure 2. The BET surface area, pore volume, and pore size were calculated to be $712 \mathrm{~m}^{2} / \mathrm{g}^{1}, 0.75 \mathrm{~cm}^{3} / \mathrm{g}$, and $3.3 \mathrm{~nm}$, respectively. Nitrogen sorption isotherms further confirmed the existence of nanoporous structure, which gave the pore size distribution curve calculated from the adsorption branch by the BJH model. The pore size distribution of $n-C S$ was narrow, indicating that the $\mathrm{n}-\mathrm{CS}$ had a uniform nanoporous structure and the pores were homogeneous.

3.2. Apatite Formation in SBF. After soaking in SBF for 7 days, it was found that the apatite deposit was covered on the n-CPC surface, and the apatite deposit showed typically spherical granules in densely packed apatite layer (Figure 3 ). High magnifications showed that the spherical particles contained many flake-like apatite crystals (Figures 3(c) and $3(\mathrm{~d}))$.

The EDX was used to examine the apatite layer on the n-CPC surface after soaking in SBF for 7 days (Figure 3(e)). The $\mathrm{Ca}$ and $\mathrm{P}$ peaks were detected, and the $\mathrm{Ca} / \mathrm{P}$ ratio of the apatite deposit was 1.61 , which was less than the $\mathrm{Ca} / \mathrm{P}$ ratio of hydroxyapatite (1.67). No apatite was found to be formed on the PLGA surface after soaking in SBF for 7 days (Figure 3(f)), indicating that pure PLGA did not have the ability to form apatite. The XRD pattern of n-CPC immersed in SBF for 7 days is shown in Figure 4. It was found that the apatite phase appeared on the n-CPC surface after immersion in SBF for 7 days.

3.3. Changes of Ion Concentration and $p H$ in SBF. The changes of concentration of $\mathrm{Ca}, \mathrm{P}$, and $\mathrm{Si}$ ions in $\mathrm{SBF}$ were examined after soaking the $\mathrm{n}-\mathrm{CPC}$ at various periods

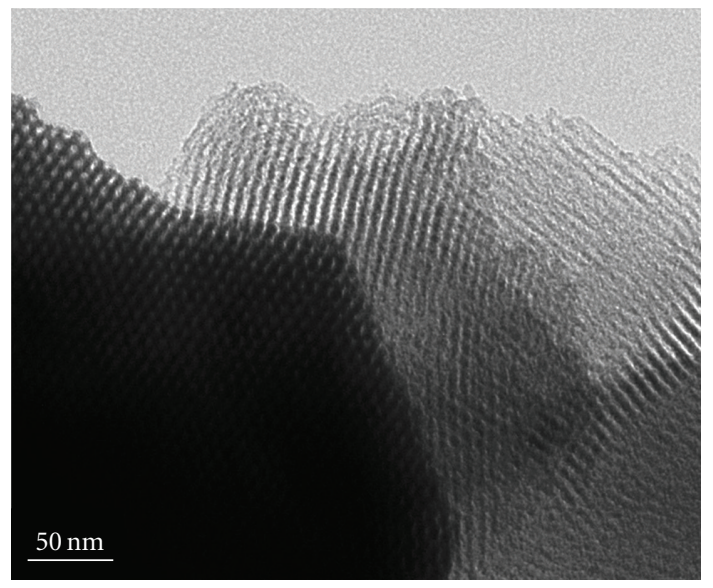

FIGURE 1: The morphology of nanoporous calcium silicate by TEM.

(Figure 5). Ca and Si ion concentrations increased quickly up to 2 days and thereafter, continued to increase at a slower rate up to 7 days. In contrast to the increasing $\mathrm{Ca}$ and $\mathrm{Si}$ ion concentrations, $\mathrm{P}$ ion concentrations decreased gradually throughout the soaking period.

The changes of $\mathrm{pH}$ value in SBF are shown in Figure 6. It was found that two different profiles of $\mathrm{pH}$ changes were evident. For the PLGA, the $\mathrm{pH}$ showed a slight decrease at the first 4 weeks followed by a rapid decrease at the last 4 weeks. At the end of 8 weeks, the $\mathrm{pH}$ stabilized at an approximate value of 4.5. For the n-CPC, the $\mathrm{pH}$ showed an increase of 7.8 during the first 1 week, then gradually decreased at a very slow rate, and stopped at 7.2, respectively, at the end of 8 weeks.

3.4. Cell Attachment. Cell attachment was assessed using $\mathrm{MG}_{63}$ cells on PLGA and n-CPC with $20 \mathrm{wt} \% \mathrm{n}-\mathrm{CS}$, respectively, and TCP as a control. The results of cell attachment efficiency were profiled in Figure 7. In a period of 4 hours, it was found that the cell attachment ratio of the n-CPC (117\%) was significantly higher than PLGA (89\%) and control $(100 \%)$. The results showed that the n-CPC facilitated cell adhesion on its surface.

3.5. Cell Proliferation. With the proliferation of the $\mathrm{MG}_{63}$ cells on PLGA, n-CPC with $20 \mathrm{wt} \% \mathrm{n}$-CS was assessed using MTT assay because optical density (OD) could provide an indicator of the cells proliferation on the different materials. It was found from Figure 8 that the OD for n-CPC was significantly higher than that of PLGA at 3 days and 5 days. The results showed that the $\mathrm{n}-\mathrm{CPC}$ could promote cell proliferation.

3.6. Morphology and Microstructure of n-CPC Scaffolds. Figure 9 shows the surface morphology and microstructure of the n-CPC porous scaffolds with $20 \mathrm{wt} \% \mathrm{n}$-CS under various magnifications. The $\mathrm{n}-\mathrm{CPC}$ scaffold exhibited a macroporous structure with completely open and interconnected pores. By SEM, the pores appeared in irregular 


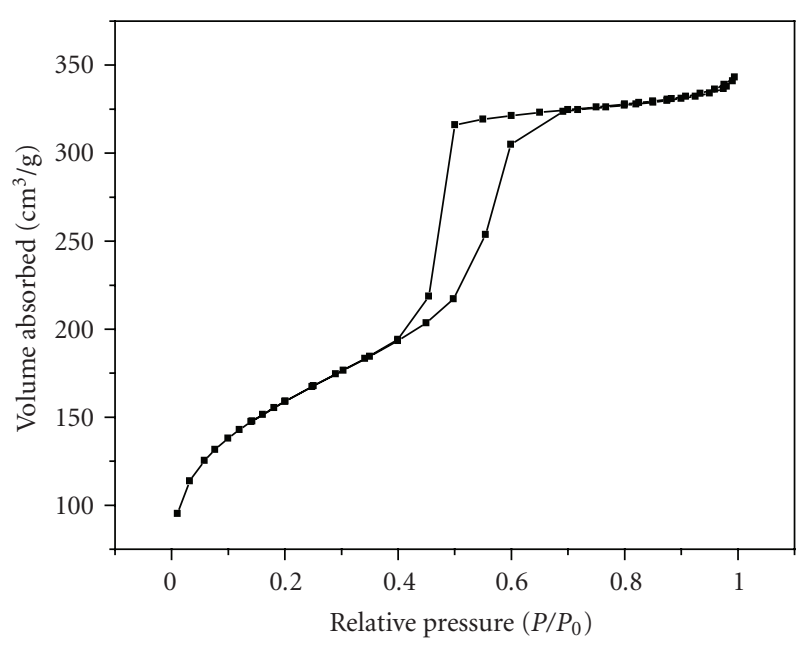

(a)

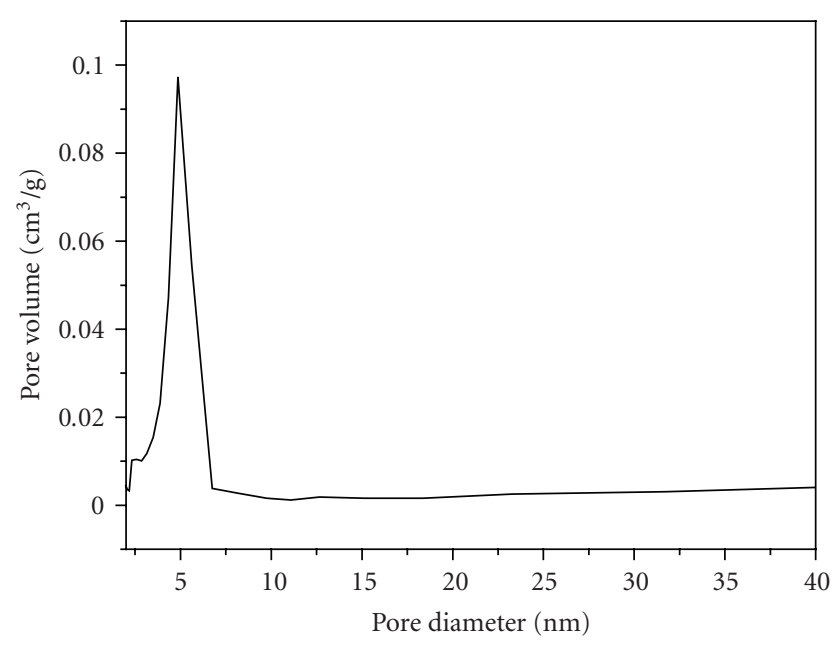

(b)

FIGURE 2: $\mathrm{N}_{2}$ sorption isotherms (a) and the pore size distribution of $\mathrm{n}-\mathrm{CS}(\mathrm{b})$.

shape, with the diameter size from 200 to $500 \mu \mathrm{m}$ as shown in Figure 9(a). High-magnification SEM images further revealed that a number of small irregular pores (around $3 \mu \mathrm{m}$ ) were distributed across the macropore walls shown in Figure 9(b).

3.7. Histological Evaluation of n-CPC Scaffolds. Histological evaluation results of the $\mathrm{n}$-CPC scaffolds implanted in the bone defects of rabbit femora are shown in Figure 10. After 2 weeks implantation, the n-CPC scaffolds were encapsulated by bone tissue, and the material started to degrade from the edge of the scaffold. After 4 weeks, some new bone tissues formed and grew into the pores of the scaffold. Material resorption at the bone-material interface was prominent. After 8 weeks implantation, the resorption of the material continued during the new bone formation in many areas of the scaffold. The boundary between the material and host bone was unclear due to the sufficient formation of mature bone tissues that had grown into the pores of the scaffolds. After 12 weeks, most of the original n-CPC scaffolds were replaced with the new formed bone.

\section{Discussion}

Bioactive biomaterials can form apatite on their surfaces when in contact with simulated body fluid (SBF) [18]. Apatite on the bioactive implant surface plays an essential role in the formation, growth, and maintenance of the tissuebiomaterial interface [19]. In this study, the n-CS as a filler was incorporated into PLGA to form bioactive n-CPC, which showed the good ability to form apatite on the composite surfaces upon soaking in SBF, indicating that $n-C P C$ had good bioactivity. Apatite could not form on the pure PLGA surface after soaking in SBF for 7 days, indicating that pure PLGA was not a bioactive biomaterial.

The $\mathrm{Ca}$ and $\mathrm{Si}$ ion concentrations in SBF increased with time during the soaking period. This increase was attributed to the dissolution of $\mathrm{Ca}$ and $\mathrm{Si}$ ions from the composite into SBF. Although the apatite formation consumed some $\mathrm{Ca}$ ions, $\mathrm{Ca}$ ion dissolution from the composite exceeded its consumption. The P ion concentration in SBF decreased gradually throughout the soaking period. The decrease of $\mathrm{P}$ ion concentration was attributed to the apatite formation, providing an indirect indication that an apatite precipitation reaction had occurred. The SEM and XRD results showed that the apatite appeared on the n-CPC surface after immersion in SBF. The EDX results revealed that the apatite formed on the n-CPC was calcium-deficient apatite with $\mathrm{Ca} / \mathrm{P}$ molar ratio of 1.61 . Obviously, the analysis of EDX results is consistent with the results from SEM and XRD.

The mechanism of apatite formation on apatitewollastonite ceramics in SBF is $\mathrm{Ca}^{2+}$ release and ionic interchange of $\mathrm{Ca}^{2+}$ for $2 \mathrm{H}^{+}$, resulting in the formation of an amorphous silica layer on its surface and providing a favorable site for apatite nucleation [20, 21]. A study indicated that the silica xerogels with high specific surface area and mesoporous structure exhibited a significantly higher amount of apatite formed on its surfaces [22]. In this study, the dissolution of n-CS increased the ionic activity product of apatite in SBF, thereby promoted the nucleation of apatite. Moreover, the n-CS with nanoporous structure and high specific surface area in the composite might improve the bioactivity of the $n-C P C$ because the larger surface area could facilitate ion exchanges and apatite surface formation by dissolution and reprecipitation process. The profile of change of $\mathrm{Ca}, \mathrm{Si}$, and $\mathrm{P}$ ion concentrations in $\mathrm{SBF}$ was similar to those of bioactive apatite-wollastonite ceramics. Therefore, the mechanism of the apatite formation on the n-CPC surface was similar to that of bioactive apatite-wollastonite ceramics.

A study has shown that the acidic degradation product of the poly (a-hydroxy acids), such as polylactide acid (PLA), polyglycolic acid (PGA) polymers, and their copolymer PLGA, resulted in $\mathrm{pH}$ decrease in the vicinity of the biomaterials [23]. In this study, the $\mathrm{pH}$-compensation ability of 


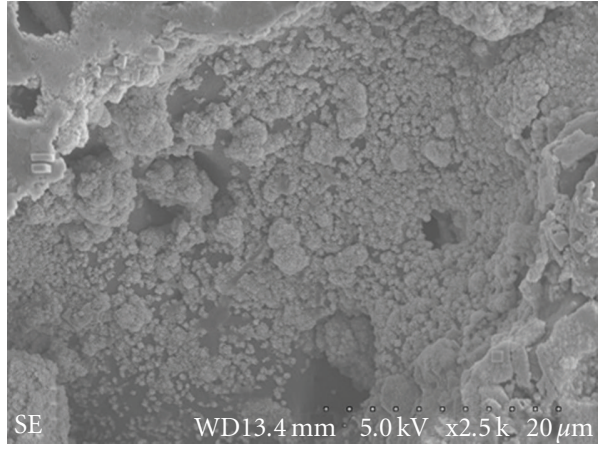

(a)

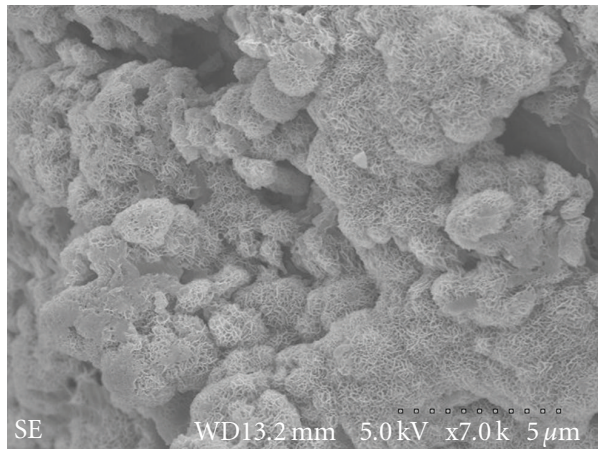

(c)

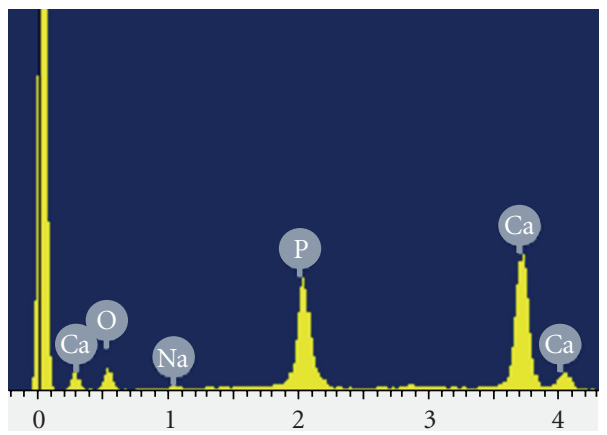

(e)

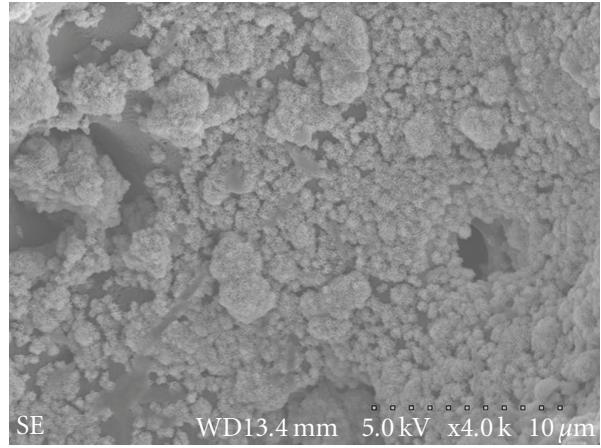

(b)

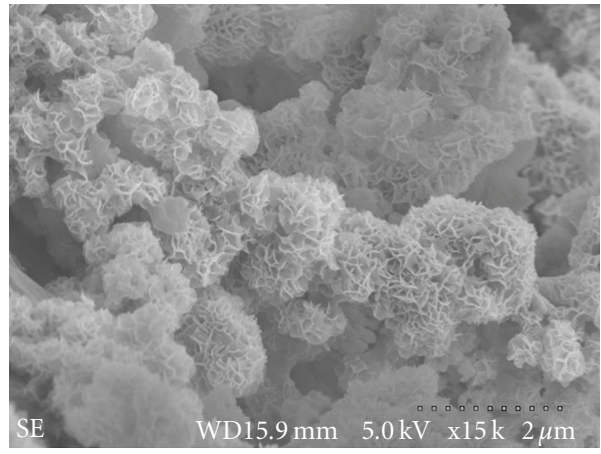

(d)

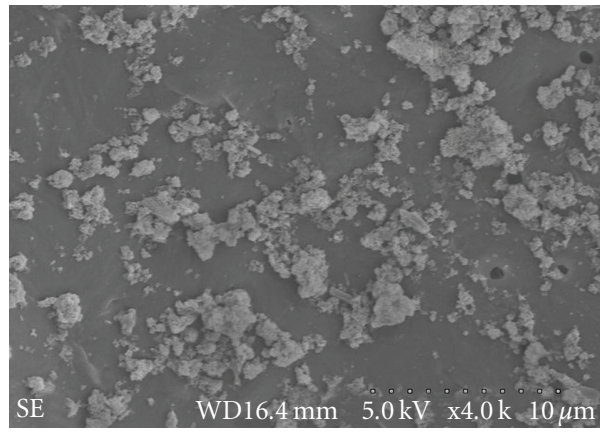

(f)

FIGURE 3: SEM images (a), (b),(c), and (d) at different magnifications and EDS (e) of n-CPC immersed in SBF for 7 days, and SEM image of PLGA (f).

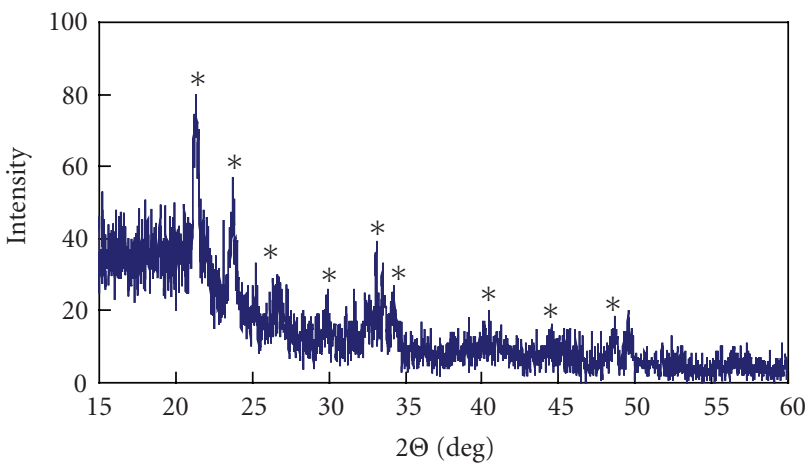

FIGURE 4: XRD pattern of $\mathrm{n}$-CPC immersed in SBF for 7 days. * represent apatite phase. bioactive inorganic $\mathrm{n}-\mathrm{CS}$ on the acidic degradation products of PLGA was evaluated. The results indicated that the $\mathrm{pH}$ value of the PLGA fell to 4.5 in 8 , weeks while the $\mathrm{pH}$ of the composite containing $20 \mathrm{wt} \% \mathrm{n}$-CS was maintained between 7.8 and 7.2 throughout the soaking period. It can be suggested that the incorporation of n-CS into PLGA was effective in compensation of the $\mathrm{pH}$ decrease caused by the acidic degradation products of the PLGA.

Bioactive implants may provide a suitable substrate for osteoblast-like cell adhesion, proliferation, and function, which would provide a strong bond between the implanted material and the surrounding bone tissue [24]. In the present study, the cell attachment tests showed that the $\mathrm{MG}_{63}$ cells adhered better to n-CPC than PLGA within the first $4 \mathrm{~h}$ of 


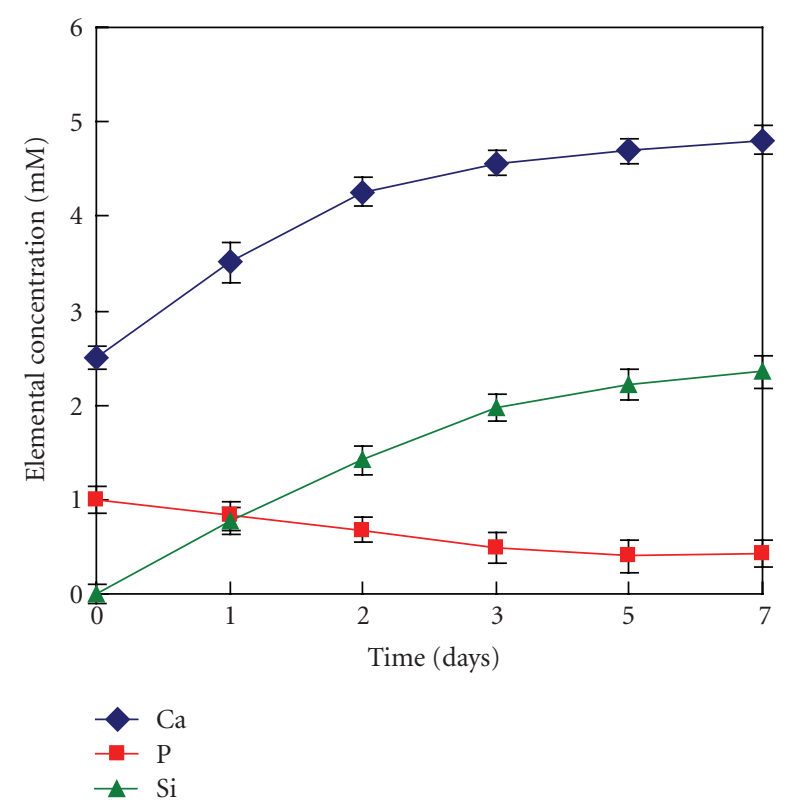

FIGURE 5: Changes of ion concentrations in SBF solution for $\mathrm{n}-\mathrm{CPC}$ after immersing for 7 days.

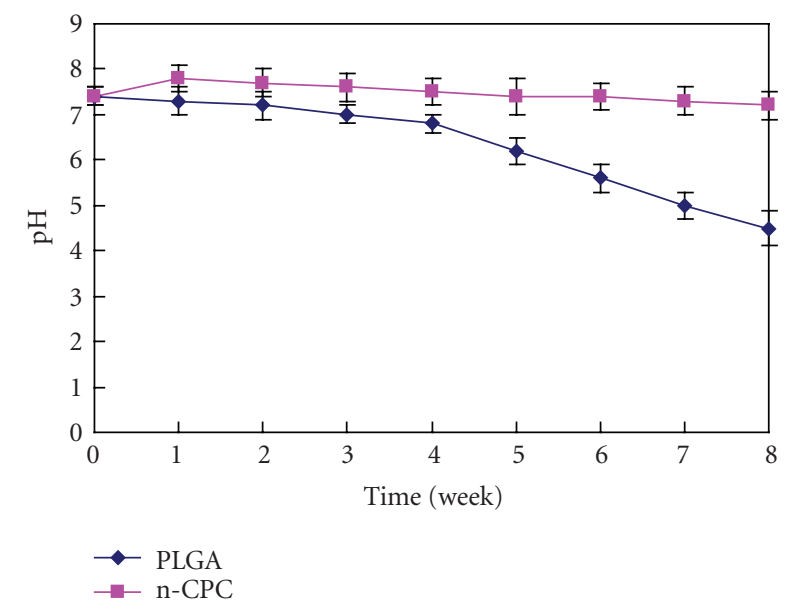

Figure 6: Changes of $\mathrm{pH}$ of SBF solution after n-CPC and PLGA immersing for 8 weeks, respectively.

cell culture due to the presence of $\mathrm{n}$-CS in the composite. Thus, the addition of n-CS into PLGA provided a good environment (surface) for cell attachment. Furthermore, nCPC might have good adsorbability due to the presence of nanoporous structure and high specific surface area of nCS, which might improve the attachment of the cell on its surface.

There are some reports that ionic dissolution products containing $\mathrm{Ca}$ and $\mathrm{Si}$ from bioactive glasses could stimulate osteoblast proliferation [25]. Xynos et al. showed that ionic products, $\mathrm{Si}$ and $\mathrm{Ca}$ in particular, could stimulate osteoblast proliferation and gene expression [26]. The ICP results showed that $\mathrm{Si}$ and Ca ions could be released from the $\mathrm{n}-\mathrm{CPC}$ into SBF. MTT tests showed that the n-CPC significantly stimulated $\mathrm{MG}_{63}$ proliferation than PLGA. Therefore, the

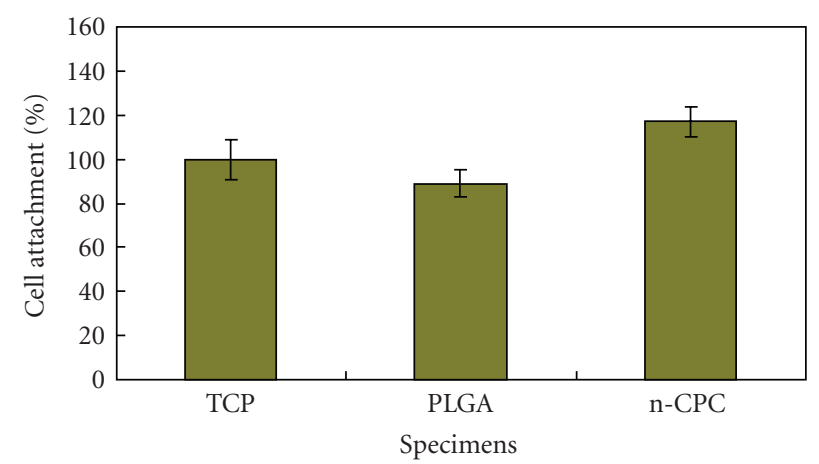

FIGURE 7: Attachment of $\mathrm{MG}_{63}$ cells on PLGA and n-CPC samples, respectively, using TCP as a control.

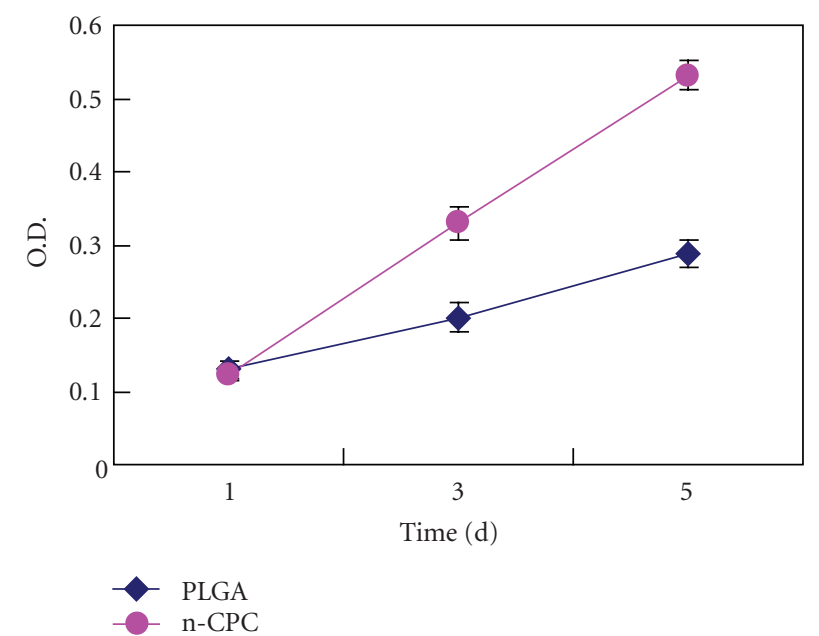

FIGURE 8: Proliferation of $\mathrm{MG}_{63}$ cells on PLGA and n-CPC samples, respectively.

dissolution associated with the $\mathrm{n}-\mathrm{CPC}$ produced a calciumand silicon-rich environment that might be responsible for stimulating cell proliferation. The $\mathrm{n}-\mathrm{CPC}$ had good bioactive surface because of the presence of bioactive nanoporous calcium silicate with high surface area, which was favorable for cell adhesion and growth, which implied good biocompatibility.

A porous scaffold is important as a temporary carrier for implanted cells in bone tissue engineering, and the scaffolds should have highly interconnected pore structure [27]. In this study, the n-CPC scaffolds were fabricated by solvent-casting and particulate-leaching methods. These nCPC scaffolds exhibited a homogeneous distribution of open macropores and pore sizes mainly in the range from 200 to $500 \mu \mathrm{m}$. Moreover, this study revealed that the $\mathrm{n}$-CPC scaffold had a good degree of interconnection. Therefore, the characteristic of the n-CPC scaffolds was likely beneficial in facilitating cell infiltration and bone ingrowth.

It was found that some small pores with the size of around $2 \mu \mathrm{m}$ were dispersed on the macroporous walls of the $\mathrm{n}$-CPC scaffolds and may have been introduced during evaporation of the solvent. Moreover, the nanoporous CS 


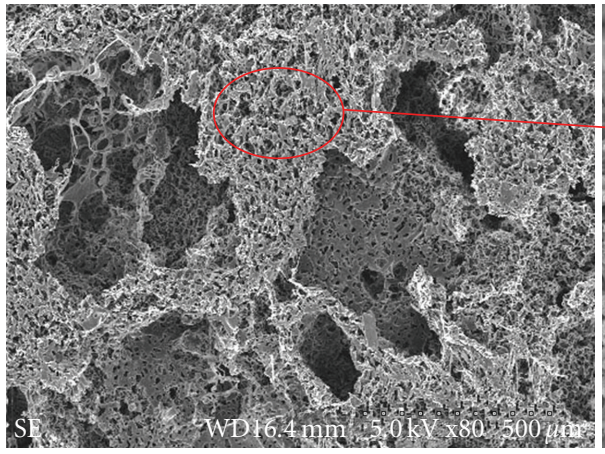

(a)

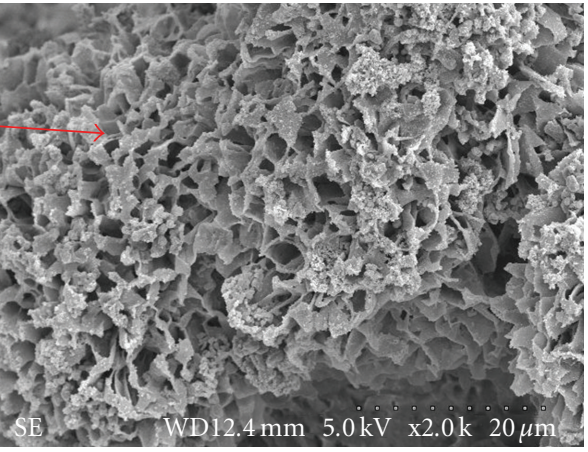

(b)

FIGURE 9: SEM photographs of n-CPC scaffold under different magnifications, (a) x80 and (b) x2000.

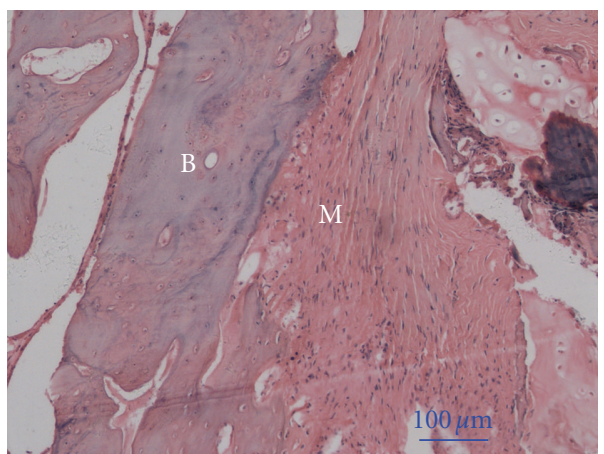

(a)

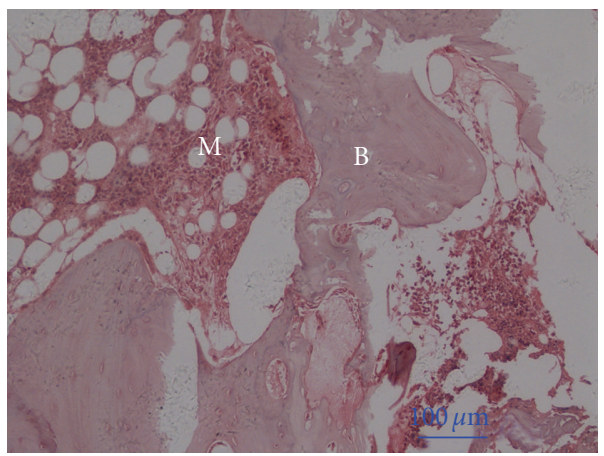

(c)

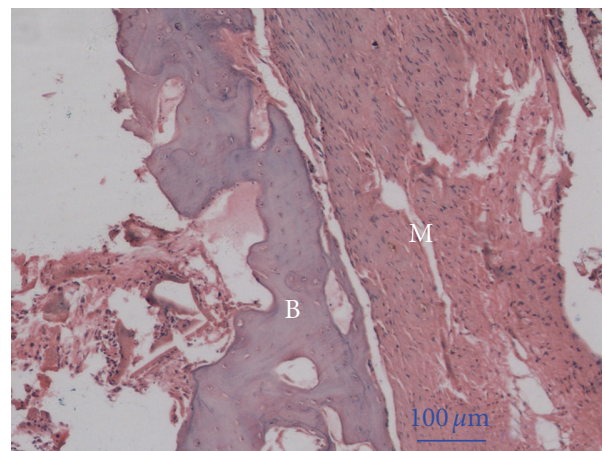

(b)

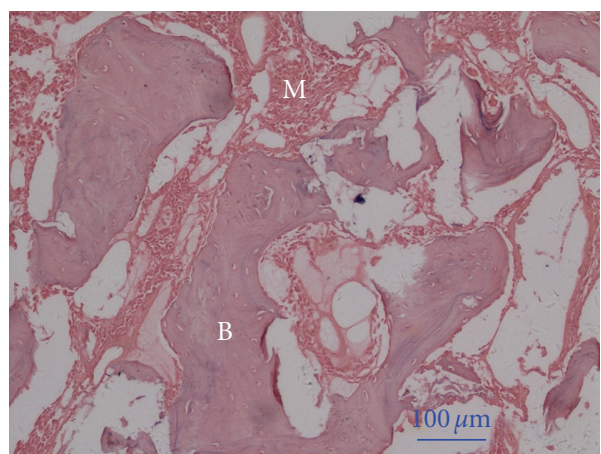

(d)

Figure 10: H\&E stained section of n-CPC scaffolds implantation into bone defects of rabbit femora for 2 (a), 4 (b), 8 (c), and 12 weeks (d). $\mathrm{M}$ represents gradually degraded materials, and $\mathrm{B}$ represents new bone tissue, respectively.

with high specific surface area was also in the composite; these small pores and nanopores might play important roles in the performances of the n-CPC scaffold. The micropores and nanopores in the macroporous scaffold surface enlarged greatly the surface area that facilitated protein adsorption on its surface; more proteins absorbed on pore surface and the easier formed apatite layer may facilitate bone formation. Yuan et al. reported that micropores on the macroporous walls of a calcium phosphate ceramic were important in osteoinduction and could induce bone formation [28]. Therefore, the nanopores and small pores on the macroporous surface of the n-CPC scaffolds may help improve the biological performance of the scaffolds.

The degradation of the biocompatible materials has been addressed in many studies, and chemical dissolution and cell-mediated resorption have been suggested for these biomaterials [29]. In this study, the degradation of the n-CPC scaffolds was observed through the 12-week implantation in the bone defects of rabbit. As the implantation time prolonged, new bone regenerated and gradually penetrated into the scaffolds, accompanied by the resorption of the materials. It is possible that the chemical dissolution and resorption 
of n-CPC occurred at the early stage of implantation. The dissolution at initial stage enlarged the microstructure of the scaffolds, and osteoclastic cells in bone also affected the degradation of the scaffolds by creating a local acidic environment, which might facilitate cell-mediated resorption later [30]. In addition, the nanoporous structure of CS and micropores in the macroporous n-CPC scaffold enlarged greatly its surface area, which might promote the degradation of the composite both in vitro and vivo.

The area of n-CPC scaffolds continued to decrease, while the newly formed bone gradually increased, indicating that a cell-mediated resorption of n-CPC occurred. New bone was found to be deposited directly on the surface of n$\mathrm{CPC}$ while the material resorption continued. Histological analysis results confirmed that n-CPC scaffolds exhibited not only degradability but also faster and more effective osteogenesis at the defect area.

\section{Conclusion}

Nanoporous calcium silicate (n-CS) with high specific surface area was synthesized using mixed surfactants of P123 and CTAB as templates, and its composite with poly (lactic acid-co glycolic acid) (PLGA) was fabricated. The n-CS/PLGA composite (n-CPC) was bioactive due to the apatite that could form on its surface after immersion in SBF for 7 days. The apatite formed on n-CPC surface through the release of $\mathrm{Ca}$ and $\mathrm{Si}$ ions from n-CS. The nCPC could improve the cell attachment rate on its surface as compared with PLGA. In addition, cell proliferation ratio, on $n-C P C$ significant higher pure PLGA, indicating $n-$ CPC could promote cells growth. The results demonstrated initial in vitro bioactivity and cytocompatibility of n-CPC. Histological evaluation confirmed that n-CPC scaffolds exhibited not only degradability but also osteogenesis in the bone defect area. Nanoporous calcium silicate with high specific surface area in the composite obviously enhanced the bioactivity and biocompatibility of the n-CPC scaffolds, and therefore, promoted bone regeneration.

\section{Acknowledgment}

This study was supported by Nano special program of Science and Technology Development of Shanghai (no. 0852nm04300).

\section{References}

[1] C. Wu, J. Chang, W. Zhai, S. Ni, and J. Wang, "Porous akermanite scaffolds for bone tissue engineering: preparation, characterization, and in vitro studies," Journal of Biomedical Materials Research, vol. 78, no. 1, pp. 47-55, 2006.

[2] S. Ni, J. Chang, L. Chou, and W. Zhai, "Comparison of osteoblast-like cell responses to calcium silicate and tricalcium phosphate creamics in vitro," Journal of Biomedical Materials Research, vol. 80, no. 1, pp. 174-183, 2007.

[3] J. Wei, F. P. Chen, J. W. Shin et al., "Preparation and characterization of bioactive mesoporous wollastonitePolycaprolactone composite scaffold," Biomaterials, vol. 6, p. 1080, 2009.
[4] W. Zhao and J. Chang, "Preparation and characterization of novel tricalcium silicate bioceramics," Journal of Biomedical Materials Research A, vol. 73, no. 1, pp. 86-89, 2005.

[5] X. Liu and C. Ding, "Plasma sprayed wollastonite/ $/ \mathrm{TiO}_{2}$ composite coatings on titanium alloys," Biomaterials, vol. 23, no. 20, pp. 4065-4077, 2002.

[6] H. Li and J. Chang, "Fabrication and characterization of bioactive wollastonite/PHBV composite scaffolds," Biomaterials, vol. 25, no. 24, pp. 5473-5480, 2004.

[7] W. D. Dai, N. K. Kawaoe, X. T. Lin, J. Dong, and G. P. Chen, "The influence of structural design of PLGA/collagen hybrid scaffolds in cartilage tissue engineering," Biomaterials, vol. 31, no. 8, pp. 2141-2152, 2010.

[8] H. Li and J. Chang, "In vitro degradation of porous degradable and bioactive PHBV/wollastonite composite scaffolds," Polymer Degradation and Stability, vol. 87, no. 2, pp. 301-307, 2005.

[9] J. Wei, S. J. Heo, D. H. Kim, S. E. Kim, Y. T. Hyun, and J. W. Shin, "Preparation and characterization of bioactive calcium silicate and poly(epsilon-caprolactone) nanocomposite for bone tissue regeneration," Journal of Biomedical Materials Research A, vol. 90, p. 702, 2009.

[10] J. Wei, S. J. Heo, D. H. Kim, S. E. Kim, and J. W. Shin, "Comparison of physical, chemical and cellular responses to nanoand micro-sized calcium silicate/poly(epsilon-caprolactone) bioactive composites," Journal of theRoyal Society Interface, vol. 23, p. 617, 2008.

[11] W. Xia and J. Chang, "Well-ordered mesoporous bioactive glasses (MBG): a promising bioactive drug delivery system," Journal of Controlled Release, vol. 110, no. 3, pp. 522-530, 2006.

[12] Y. Hong, X. Chen, X. Jing et al., "Preparation, bioactivity, and drug release of hierarchical nanoporous bioactive glass ultrathin fibers," Advanced Materials, vol. 22, no. 6, pp. 754$758,2010$.

[13] Y. Hong, H. Fan, and X. Zhang, "Synthesis and protein adsorption of hierarchical nanoporous ultrathin fibers," Journal of Physical Chemistry B, vol. 113, no. 17, pp. 5837-5842, 2009.

[14] J. Wei, C. S. Liu, J. F. Jia et al., Journal of the American Ceramic Society, vol. 23, p. 617, 1996.

[15] W. Cheng, H. Li, and J. Chang, "Fabrication and characterization of $\beta$-dicalcium silicate/poly(d,l- lactic acid) composite scaffolds," Materials Letters, vol. 59, no. 17, pp. 2214-2218, 2005.

[16] H. Li and J. Chang, "Preparation and characterization of bioactive and biodegradable Wollastonite/poly(D,L-lactic acid) composite scaffolds," Journal of Materials Science: Materials in Medicine, vol. 15, no. 10, pp. 1089-1095, 2004.

[17] X. Liu, C. Ding, and Z. Wang, "Apatite formed on the surface of plasma-sprayed wollastonite coating immersed in simulated body fluid," Biomaterials, vol. 22, no. 14, pp. 2007-2012, 2001.

[18] H. Takadama, H.-M. Kim, T. Kokubo, and T. Nakamura, "TEM-EDX study of mechanism of bonelike apatite formation on bioactive titanium metal in simulated body fluid," Journal of Biomedical Materials Research, vol. 57, no. 3, pp. 441-448, 2001.

[19] C. Wu and J. Chang, "Synthesis and apatite-formation ability of akermanite," Materials Letters, vol. 58, no. 19, pp. 24152417, 2004.

[20] T. Kokubo, S. Ito, Z. T. Huang et al., "Ca, P-rich layer formed on high-strength bioactive glass-ceramic A-W," Journal of Biomedical Materials Research, vol. 24, no. 3, pp. 331-343, 1990. 
[21] X. Liu, C. Ding, and P. K. Chu, "Mechanism of apatite formation on wollastonite coatings in simulated body fluids," Biomaterials, vol. 25, no. 10, pp. 1755-1761, 2004.

[22] X. Wu, J. Wei, X. Lu et al., "Chemical characteristics and hemostatic performances of ordered mesoporous calciumdoped silica xerogels," Biomedical Materials, vol. 5, no. 3, p. 9, 2010.

[23] H. Li and J. Chang, "pH-compensation effect of bioactive inorganic fillers on the degradation of PLGA," Composites Science and Technology, vol. 65, no. 14, pp. 2226-2232, 2005.

[24] N. Olmo, A. I. Martín, A. J. Salinas, J. Turnay, M. Vallet-Regí, and M. A. Lizarbe, "Bioactive sol-gel glasses with and without a hydroxycarbonate apatite layer as substrates for osteoblast cell adhesion and proliferation," Biomaterials, vol. 24, no. 20, pp. 3383-3393, 2003.

[25] V. Patricia, M. P. Marivalda, M. G. Alfredo, and L. Fatima, "The effect of ionic products from bioactive glass dissolution on osteoblast proliferation and collagen production," Biomaterials, vol. 25, no. 15, pp. 2941-2948, 2004.

[26] I. D. Xynos, A. J. Edgar, L. D. K. Buttery, L. L. Hench, and J. M. Polak, "Gene-expression profiling of human osteoblasts following treatment with the ionic products of Bioglass $\mathbb{R}$ 45S5 dissolution," Journal of Biomedical Materials Research, vol. 55, no. 2, pp. 151-157, 2001.

[27] C. M. Murphy, M. G. Haugh, and F. J. O’Brien, “The effect of mean pore size on cell attachment, proliferation and migration in collagen-glycosaminoglycan scaffolds for bone tissue engineering," Biomaterials, vol. 31, no. 3, pp. 461-466, 2010.

[28] H. Yuan, Z. Yang, Y. Li, X. Zhang, J. D. de Bruijn, and K. de Groot, "Osteoinduction by calcium phosphate biomaterials," Journal of Materials Science: Materials in Medicine, vol. 9, no. 12, pp. 723-726, 1998.

[29] Y. Huang, X. Jin, X. Zhang et al., "In vitro and in vivo evaluation of akermanite bioceramics for bone regeneration," Biomaterials, vol. 30, no. 28, pp. 5041-5048, 2009.

[30] K. Cheng, Y. Lai, and W. S. Kisaalita, "Three-dimensional polymer scaffolds for high throughput cell-based assay systems," Biomaterials, vol. 29, no. 18, pp. 2802-2812, 2008. 

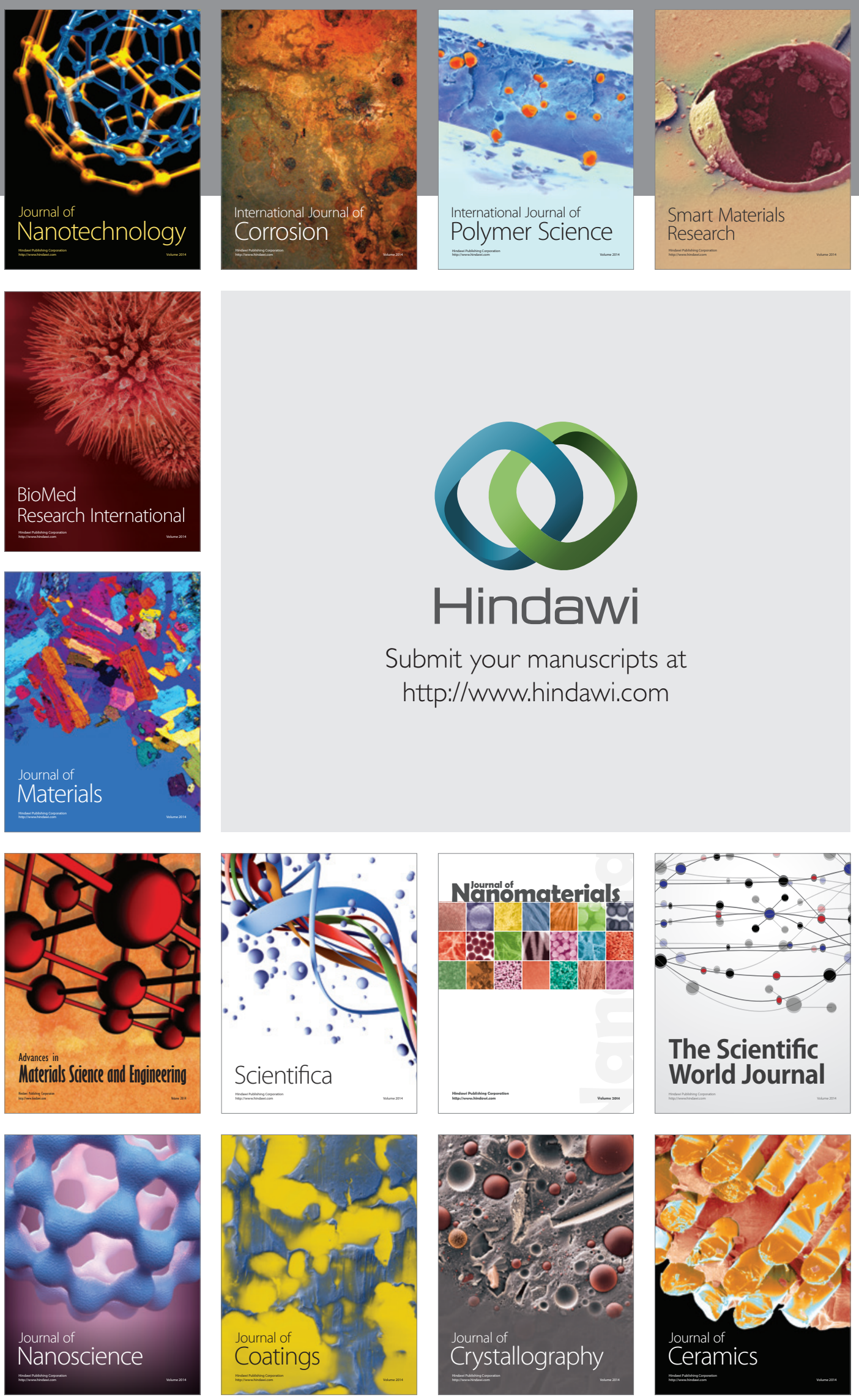

The Scientific World Journal

Submit your manuscripts at

http://www.hindawi.com

\section{World Journal}

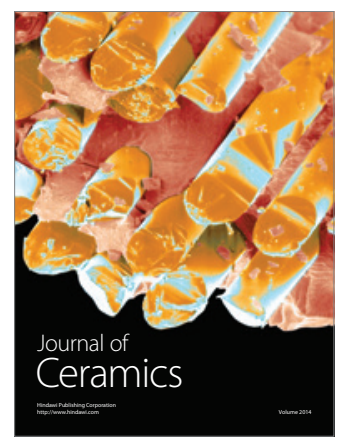

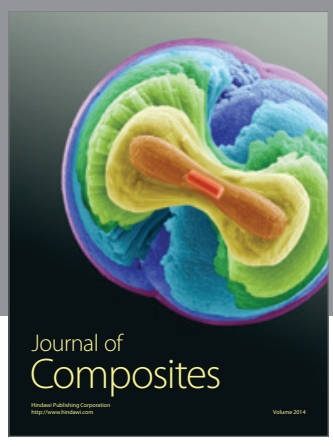
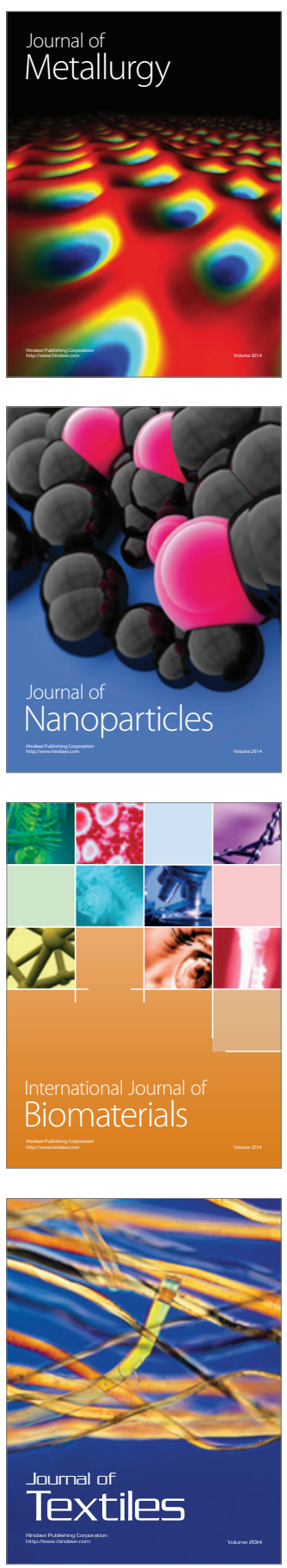